\title{
Treatment with cyclosporin and risks of graft rejection in male kidney and heart transplant recipients with non-O blood
}

\author{
G F J Hendriks, E P M v Steenberge, G M Th Schreuder, G J Wenting, B Mochtar, E Bos, \\ M L Simoons, A H M M Balk, K Laird-Meeter, C E Essed, D Baumgartner, J Jeekel, W Weimar
}

\begin{abstract}
In a consecutive series of 146 kidney transplant recipients treated with cyclosporin $A$ a strong correlation between matching for the HLA-A, HLA-B, and HLA-DR loci specificities and outcome of the grafts was observed in male recipients with non-0 blood groups. Such a beneficial effect of matching was not found in female patients or male patients with blood group 0 . In these patients survival of the grafts at one year was good irrespective of the number of HLA-A, B, and DR mismatches. Also in 47 male heart transplant recipients immune responsiveness against mismatched HLA antigens was related to blood group. A significantly higher incidence of rejection episodes was observed in male patients with non-O blood groups $(n=32)$ than in those with blood group $O(n=15)$. Matching for HLA-DR reduced the number of acute rejection episodes in male patients with non-O blood.

These findings may help explain the controversial reports about the importance of HLA matching in organ transplantation. Furthermore, as most candidates for heart transplantation are male and not of blood group $\mathbf{O}$, the higher incidence of graft rejection in these patients underscores the need for an exchange strategy of donor hearts.
\end{abstract}

\section{Introduction}

In 1977 Opelz and Terasaki showed that male patients with non-O blood groups who had been given kidney grafts poorly matched for HLA-A and B loci specificities were at high risk of graft failure. ${ }^{1}$ Though this difference in immune responsiveness was confirmed, ${ }^{2}$ most follow up analyses of patients with transplants failed to take this interaction into account. To some extent this omission may be explained by the introduction of cyclosporin $\mathrm{A},{ }^{3}$ which seemed to overshadow the importance of HLA matching by improving graft survival, especially in recipients of poorly matched grafts. ${ }^{+}$Nevertheless, we wondered whether the influence of blood group, sex, and HLA matching was still relevant in the cyclosporin era.

Selection of donors and recipients of renal allografts is based on HLA matching, so that these recipients are a biased group with respect to the proportion with well matched and poorly matched grafts. By contrast, in heart transplantation selection of donors and recipients is not based on HLA matching. Furthermore, routine serial endomyocardial biopsy specimens are taken frequently during the first postoperative year, so that we know the exact number of acute rejection episodes.
Heart transplantation therefore affords a unique opportunity to study the effect of the interaction between ABO blood type and HLA matching on the immune responsiveness against allograft antigens.

\section{Patients and methods}

Only patients with their first grafts were included in the analysis. All operations were performed at this centre between January 1984 and December 1987, and the series comprised 146 renal allograft and 55 heart transplant recipients. All renal allograft recipients received at least one blood transfusion before operation. Only one of the 55 heart transplant recipients did not receive a formal blood transfusion. Four early deaths none due to immunological failures - were excluded from the group of heart transplant recipients.

HLA typing of all patients was performed in duplicate at the National Reference Centre for Histocompatibility Testing in Leiden. "Acute" HLA typing of donors was performed either at this institute or at one of the tissue typing laboratories collaborating in Eurotransplant. HLA-DR serum samples were available for recognition of specificities DR 1, 2, 3, 4, 5, 6, 7, 8,9 , and 10 . The degree of standardisation of tissue typing among the collaborating institutions has been reported. Selection of donors and recipients was based on matching for the main HLA-A, B, and DR specificities, not for their splits. Before transplantation a crossmatch test was performed with the most recent serum sample from the potential recipient and if necessary with previous serum samples containing lymphocytotoxic antibodies. Results of the crossmatch test was considered positive when more than $10 \%$ of the donor lymphocytes were killed. Donor specific sensitisation was considered a contraindication to transplantation.

The immunosuppressive regimen in both groups of recipients consisted of cyclosporin for at least one year and low dose steroids. Biopsy proved acute rejection crises were treated with either methylprednisolone or rabbit antithymocyte globulin. Renal transplant recipients who died with a functioning graft were considered to have had graft failures. The impact of $A B O$ and HLA-DR mismatches on graft outcome in the 51 heart transplant recipients ( 49 of whom survived) was analysed in terms of the incidence of acute rejection episodes as a marker of immune responsiveness. Endomyocardial biopsy specimens were taken weekly during the first six weeks after transplantation, every two weeks during the next six weeks, and monthly thereafter. Graft survival times were calculated by the actuarial life table method. ${ }^{6}$ The significance of differences among the various groups of patients was analysed by $\chi^{2}$ test. matched (two to four $A, B$ mismatches) kidney grafts in blood group $O$ and non-blood group $O$ female and male recipients. (Whole numbers of patients in parentheses)

\begin{tabular}{|c|c|c|c|c|c|c|}
\hline \multirow[b]{2}{*}{ A, B Mismatches } & \multicolumn{3}{|c|}{ Female recipients } & \multicolumn{3}{|c|}{ Male recipients } \\
\hline & $\mathrm{O}$ & Non-O & Total & $\mathrm{O}$ & Non-O & Total \\
\hline $\begin{array}{l}0 \text { Or } 1 \\
2-4\end{array}$ & $\begin{array}{l}91(12) \\
83(14)\end{array}$ & $\begin{array}{l}78(19) \\
92(26)\end{array}$ & $\begin{array}{l}83(31) \\
89(40)\end{array}$ & $\begin{array}{l}91(14) \\
87(16)\end{array}$ & $\begin{array}{l}91(22) \\
50(23)\end{array}$ & $\begin{array}{l}91(36) \\
65(39)\end{array}$ \\
\hline Overall & $85(26)$ & $87(45)$ & $85(71)$ & $89(30)$ & $69(45)$ & $76(75)$ \\
\hline Significance ${ }^{\star}$ & $p>0.9$ & $\mathrm{p}<0.05$ & $\mathrm{p}>0 \cdot 1$ & $p>0.4$ & $\mathrm{p}<0.005$ & $p<0.06$ \\
\hline
\end{tabular}

^Tested by $\chi^{2}$ test derived from log rank analysis.

\section{Results}

KIDNEY TRANSPLANTS

No beneficial effect of HLA-A and B matching was detected in the total group of 71 female renal transplant recipients (table I). The one year survival rate of HLAA and B well matched (none or one A or B mismatch) grafts was $83 \%$ compared with $89 \%$ in the poorly matched (two to four A and B mismatches) group. Further subdivision of these patients into those with 
group $\mathrm{O}$ and non-group $\mathrm{O}$ blood types disclosed a significantly better outcome for poorly matched grafts in the non-O group $(78 \% v 92 \% ; \mathrm{p}<0.05)$. The poorer outcome of 19 HLA-A and B well matched grafts in female recipients with non-O blood $(78 \%$ graft survival at one year) was due to four graft failures. Three grafts failed in highly immunised patients, in whom HLA-A and B matching does not improve graft prognosis.' By contrast, a beneficial effect of HLA-A and B matching was found in the 75 male kidney transplant recipients. The one year survival rate of HLA-A and B well matched grafts was $91 \%(n=36)$ compared with $65 \%(n=39)$ in the poorly matched group $(p<0.06)$. The red cell type of male recipients influenced the relation between degree of matching and graft outcome very significantly. In recipients with blood group $\mathrm{O}$ there was no correlation with HLA-A and $B$ matching $(p>0.4)$, whereas a highly significant effect was found in recipients with non-O blood groups. The one year graft survival rate in 22 nongroup $\mathrm{O}$ male recipients of HLA-A and B well matched grafts was $91 \%$ compared with $50 \%$ in the poorly matched group $(n=23 ; p<0.005)$.

The phenomenon of immune responsiveness against HLA-A and B mismatched antigens restricted to male patients with non-O blood types was also valid for HLA-DR matching. The difference in one year kidney graft survival between 17 HLA-DR matched and 28 HLA-DR mismatched grafts transplanted into nonblood-group $\mathrm{O}$ male recipients was $41 \%(\mathrm{p}=0.003)$. In male recipients with blood group $O$ the one year survival rates of HLA-DR matched $(n=9)$ and HLADR mismatched $(n=21)$ grafts were $89 \%$ and $87 \%$ respectively (figure). No significant difference in
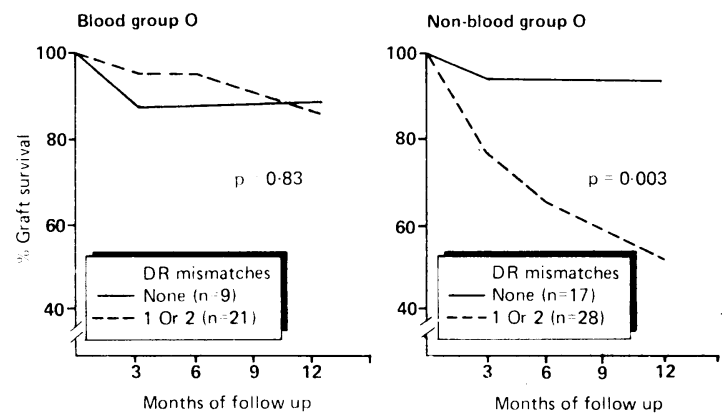

Influence of HLA-DR matching (none versus one or two DR mismatches) on one year survival of first kidney grafts in blood group $O$ and non-blood-group $O$ male recipients. ( $p$ Values tested by $\chi^{2}$ test derived from log rank analysis ${ }^{6}$ )

mortality between male recipients with blood groups $\mathrm{O}$ (one out of 21) and non-O (three out of 28) was observed that might have explained the inferior outcome in non-O male recipients of HLA-DR mismatched grafts. In female recipients no beneficial effect of HLA-DR matching was observed, one year survivals of $89 \%$ and $83 \%$ being found for HLA-DR matched $(n=29)$ and HLA-DR mismatched grafts $(n=$ $42)$ respectively $(p>0 \cdot 8)$. Further subdivision of female recipients into those with group $\mathrm{O}$ and non-O blood did not influence the results appreciably.

heart transplant recipients with group $O$ and non-group $O$ blood who suffered none or one, or two or more acute episodes of rejection

\begin{tabular}{|c|c|c|c|}
\hline \multirow{2}{*}{$\begin{array}{l}\text { No of acute } \\
\text { rejection } \\
\text { episodes }\end{array}$} & \multicolumn{2}{|c|}{ Blood group } & \multirow{2}{*}{$\begin{array}{c}\text { All } \\
\text { patients }\end{array}$} \\
\hline & $\mathrm{O}$ & Non-O & \\
\hline $\begin{array}{l}0 \text { Or } 1 \\
\geqslant 2\end{array}$ & $\begin{array}{r}14 \\
1\end{array}$ & $\begin{array}{l}16 \\
16\end{array}$ & $\begin{array}{l}30 \\
17\end{array}$ \\
\hline Total & 15 & 32 & 47 \\
\hline
\end{tabular}

Significance of difference between Significance of difference between
groups: $p<0.01 \quad\left(\chi^{2}\right.$ test with groups: $\quad \mathrm{p}<0.01$
Yates's correction). more rejection episodes (table III). By contrast, two or more rejection episodes occurred in 16 out of 28 nonblood-group O male recipients of an HLA-DR mismatched graft. No significant difference was recorded in the incidence of rejection episodes between recipients of heart grafts with one HLA-DR mismatch $(\mathrm{n}=$ 17) and those with two HLA-DR mismatches $(n=11)$. In the group with one HLA-DR mismatch 10 patients were treated for two or more rejection episodes and in the group with two HLA-DR mismatches six were so treated.

TABLE III - Numbers of male heart transplant recipients with group $O$ and non-group $O$ blood who suffered none or one, or two or more acute episodes of rejection stratified by numbers of DR mismatches (none, or one or two )

\begin{tabular}{lcccccc}
\hline & \multicolumn{2}{c}{ Blood group O } & & \multicolumn{2}{c}{ Non-blood group O } & \\
\cline { 2 - 3 } $\begin{array}{l}\text { No of DR } \\
\text { mismatches }\end{array}$ & $\begin{array}{c}\text { 0 Or 1 } \\
\text { rejection }\end{array}$ & $\begin{array}{c}\geqslant 2 \\
\text { Rejections }\end{array}$ & & $\begin{array}{c}\text { 0 Or 1 } \\
\text { rejection }\end{array}$ & $\begin{array}{c}\geqslant 2 \\
\text { Rejections }\end{array}$ & $\begin{array}{c}\text { All } \\
\text { patients }\end{array}$ \\
\hline 0 & 1 & 0 & & 4 & 0 & $\begin{array}{r}5 \\
1 \text { Or } 2\end{array}$ \\
\hline Total & 13 & 1 & & 12 & 16 & 42 \\
\hline
\end{tabular}

\section{Discussion}

In 1973, when organ donors and recipients could be typed only for the HLA-A and B loci specificities, Joysey et al noticed a significantly better graft outcome in recipients with blood group $\mathrm{O},{ }^{8}$ which they later explained by a much stronger blood transfusion effect. ${ }^{9}$ Our finding of a beneficial effect of HLA-A and B matching restricted to male kidney graft recipients with non-O blood groups confirms the report of Opelz and Terasaki. ${ }^{1}$ We also found a better outcome related to HLA-DR matching (figure), which agrees with the findings of D'Amaro et al. ${ }^{2}$ We emphasise, however, that all our patients were treated with cyclosporin, whereas patients in the quoted reports were treated with azathioprine. Thus even with cyclosporin male patients with non-O blood groups given poorly matched (HLA-A, B, and DR) kidney grafts retain strong immune responsiveness against mismatched HLA antigens. Screening for leucocytotoxic anti-HLA antibodies in our patients showed that only a minority of the male patients with non-O blood ( $3 \%$; data not shown) belonged to the so called highly immunised group. ${ }^{10}$ Our male patients apparently did not not mount a strong humoral immune response against transfused mismatched HLA antigens. Goulmy et al showed that compatibility for the HLA-B locus specificities in male patients predisposed to immune nonreactivity and good graft prognosis. ${ }^{11}$ In our study 23 out of 45 male patients with non-O blood were given kidney grafts with two to four HLA-A and B mismatches. Only two turned out to be compatible for the HLA-B locus specificities. This may explain the poor graft prognosis in these patients ( $50 \%$ graft survival at one year; table I).

Recently Eurotransplant and other organ exchange organisations-for example, the United Kingdom Transplant Service-have switched emphasis from HLA-A and B matching to HLA-DR matching in selecting donors and recipients. HLA-DR matching not only improves renal allograft prognosis ${ }^{12-16}$ but also reduces the number of acute rejection episodes, ${ }^{17} 18$ resulting in better graft function. ${ }^{1719}$ In our series of renal transplant recipients a strongly beneficial effect of HLA-DR matching was found only in male patients with non-O blood.

In heart transplantation the incidence and severity of rejection episodes may play an important part in long term graft function and survival. Thus identifying high immune responders is important. Our finding of a 
strong correlation between the incidence of acute cardiac allograft rejection and $\mathrm{ABO}$ blood group in male recipients precisely identifies such patients with high immune responsiveness. As heart transplant recipients with blood group $\mathrm{O}$ always receive $\mathrm{ABO}$ identical grafts, our observations may explain the findings of McKenzie et al, ${ }^{20}$ who observed a highly significant incidence of graft failure due to rejection in ABO incompatible donor-recipient pairs-that is, patients with non-O blood types. As our pretransplantation transfusion policy is the same for heart transplant recipients with type $\mathrm{O}$ and non-type $\mathrm{O}$ blood, it is unlikely that the low incidence of acute rejection episodes recorded in patients with type $\mathrm{O}$ blood was due to a quantitative transfusion effect. ${ }^{21}$ The low immune responsiveness against cardiac allograft antigens in these patients is also illustrated by the fact that their single acute rejection episodes were easily reversed with methylprednisolone in all cases, in contrast with the non-O group (only half the cases).

Matching for HLA-A and B loci specificities improved cardiac allograft prognosis. ${ }^{22}{ }^{23}$ Unfortunately, owing to the high polymorphism of HLA-A and B loci and the comparatively low numbers of patients awaiting cardiac transplantation only very few of them will receive a HLA-A and $\mathrm{B}$ well matched graft. But what can we achieve with HLA-DR matching in cardiac transplantation? Though at the DNA level certain HLA-DR specificities turned out to be highly polymorphic, ${ }^{2+}$ our data in the kidney transplant group (figure) and the experience of others ${ }^{13-20}$ clearly indicate that avoiding mismatches for the serologically defined main HLA-DR specificities substantially improves graft prognosis. In clinical cardiac transplantation the importance of sharing at least one HLA-DR antigen has recently been reported; Yacoub et al found a significant difference in one year survival between cardiac grafts with one and two HLA-DR mismatches ( $84 \%$ v $68 \%$ survival respectively). ${ }^{25}$ In addition, a correlation was found by Pfeffer et al between the degree of HLA-DR matching and the incidence of acute rejection episodes in cardiac transplants. ${ }^{26}$ Neither group of investigators, however, took the $\mathrm{ABO}$ state of recipients into account or reported the results with HLA-DR compatible grafts. Our preliminary data in heart transplant recipients suggest that matching for HLA-DR in male patients with nontype $\mathrm{O}$ blood may reduce the incidence of cardiac allograft rejection. Collaborative efforts should therefore be made by transplant centres to exchange HLADR compatible hearts in these patients. The rapid development of new tissue typing techniques at the DNA level ${ }^{27}{ }^{28}$ will be of great help in performing such an exchange in the near future. Problems with long term storage of hearts and the acute need of the recipients, however, may preclude this at present. Alternatively, a strategy which might be considered in recipients with non-O blood is the use of more powerful immunosuppression, both as maintenance treatment and for episodes of rejection.

Our results from a single centre serve as a reminder of an important observation first made 10 years agothat is, of the strong immune responsiveness against allograft antigens in male patients with non-O blood groups. Our data show that in the cyclosporin era this observation still holds, not only in renal transplant recipients but also in patients given heart transplants.

1 Opelz G, Terasaki PI. Influence of sex on histocompatibility matching in rena transplantation. Lancet 1977;ii:419-21.

2 D'Amaro J, Hendriks GFJ, Persijn GG, van Rood JJ. Influence of sex and ABO blood group on HLA-A, B and DR matching in renal transplantation. Transplant Proc 1985;17:758-60.

3 Calne RY, White DJG, Thiru S, et al. Cyclosporin A in patients receiving renal allografts from cadaver donors. Lancet 1978: ii:1323-7.

4 Cecka JM. The changing role of HLA-matching. In: Terasaki P, ed. Clinical transplants 1986. Los Angeles: UCLA Tissue Typing Laboratory, 1986:14156.
5 Schreuder GMTh, Hendriks GFJ, D'Amaro J, Persın GG. An eight year study of HLA-typing proficiency in Eurotransplant. Tissue Antigens 1986;27:131-4

6 Peto R, Pike MC, Armitage P, et al. Design and analysis of randomized clinical trials requiring prolonged observation of each patient. II. Analyses and examples. Br f Cancer 1977;35:1-39.

7 Hendriks GFJ. The survival of HLA-matched renal allografts in highly immunized patients. In: Touraine JL, Traeger J, Bétuel H, Dubernard JM, Revillard JP, Triau R, eds. Transplantation and clinical immunology. Vol 17. Amsterdam, New York, Oxford: Excerpta Medica, 1985:147-54.

8 Joysey VC, Roger JH, Evans DB, Herbertson BM. Kidney graft survival and matching for HLA and ABO antigens. Nature 1973;246:163-5.

9 Joysey VC, Roger JH, Evans DB, Herbertson BM. Differential kidney graft survival associated with interaction between recipient $A B O$ group and survival associated with interaction between recipient ABO
pretransplant blood transfusion. Transplantation 1977;24:371-6.

10 Hendriks GFJ, de Lange P, D'Amaro J, et al. Eurotransplant experience with high immunized patients. Scand I Urol Nephrol 1985;92 (suppl):81-6.
hel

11 Goulmy E, Persijn GG, Blokland E, Van Rood JJ. CML nonreactivity after kidney transplantation. Transplant Proc 1981;18:1607-9.

12 Persijn GG, Gabb BW, van Leeuwen A, Nagtegaal A, Hoogeboom J, van Rood JJ. Matching for HLA antigens of A,B and DR loci in renal transplantation by Eurotransplant. Lancet 1978; ;:1278-81.

13 Ting A, Morris PJ. Powerful effect of HLA-DR matching on survival of cadaveric renal allografts. Lancet 1980;ii:282-5.

14 Moen T, Albrechtsen D, Flatmark A, et al. Importance of HLA-DR matching in cadaveric renal transplantation. $N$ Engl f Med 1980;303:850-4.

15 Vanrenterghem Y, Vandeputte I, Lerut T, Roels L, Gruwez J, Michelsen P. Importance of HLA-DR matching in polytransfused cadaveric kidney transplant recipients. Transplantation 1983:36:384-7.

16 Festenstein H, Doyle ChBP, Holmes J. Long-term follow-up in London transplant group recipients of cadaver renal allografts. $N$ Engl $\mathcal{f} \mathrm{Med}$ transplant group

17 Joysey VC, Thiru S, Evans DB. Effect of HLA-DR compatibility on kidney transplants treated with cyclosporin A. Transplant Proc 1985;17:2187-92.

8 Weimar W, Hendriks GFJ, Wenting GJ, Vincent HH, Schreuder GMTh, Jeekel J. Prophylactic antilymphocyte globulin and HLA-DR matching reduce the incidence of rejection after cadaveric kidney transplantation. Transplant Proc 1987;19:3612-3.

19 Van Rood JJ, Hendriks GFJ. HLA-matching, immune status and immunosuppression. In: Touraine JL, Traeger J, Bétuel H, Dubernard JM Revillard JP, Triau R, eds. Transplantation and clinical immunology. Vol 15 . Amsterdam, New York, Oxford: Excerpta Medica, 1983:179-85.

20 McKenzie FN, Tadros N, Stiller C, Keown P, Sinclair N, Kostuk W. Influence of donor-recipient lymphocyte crossmatch and $\mathrm{ABO}$ status on rejection risk in cardiac transplantation. Transplant Proc 1987;19:3439-41.

21 Opelz G, Terasaki PI. Improvement of kidney graft survival with increased numbers of blood transfusions. N Engl $\mathrm{F}$ Med 1978;299:799-803.

22 Raffoux C, Mayor V, Cabrol C, Busson M, Hors J, Colombani J. The influence of HLA matching in cardiac allograft recipients in a single center. Transplant Proc 1987; 19:3559-60.

23 Frist WH, Oyer PhE, Baldwin JC, Stinson EB, Shumway NE. HLA compatibility and cardiac transplant recipient survival. Ann Thorac Surg $1987 ; 44: 242-6$

24 Tilanus MGJ, v Eggermond MGJA, van der Bijl M, et al. HLA class II DNA analysis by RFLP reveals novel class II polymorphisms. Hum Immunol 1987;18:265-76.

25 Yacoub M, Festenstein H, Doyle P, et al. The influence of HLA matching in cardiac allograft recipients receiving cyclosporin and azathioprine. Transplant Proc 1987; 19:2487-9.

26 Pfeffer PF, Foerster A, Froysaker T, Thorsby E. Correlation berween HLA DR mismatch and rejection episodes in cardiac transplantation. Transplant Proc 1987;19:691-2.

27 Saiki RK, Bugawan TL, Horn G, Mullis KB, Erlich AH. Analysis of enzymatically amplified beta globulin and HLA-DR alpha DNA with allele specific oliso a

28 Gorski J, Tilanus M, Giphart M. Mach B. Oligonucleotide genotyping shows that alleles at the HLA-DR beta III locus of the DRw 52 supertypic group
segregate independently of known DR or Dw specificities. Immunogenetics segregate indepenc

(Accepted 8 fune 1988)

\section{ONE HUNDRED YEARS AGO}

The long delay in promulgating officially the alterations in the regulations for the medical degrees of the University of London calls for some explanation from the Executive. These alterations were approved by the Senate as long ago as last May, and the Committee on Examinations in Arts, Science, and Laws, and the Committee on Examinations in Medicine have had the alterations before them ever since; a few hours' serious work would have sufficed to embody all the changes in the regulations and syllabuses, and the revised documents might easily have been issued before the vacation commenced. As it is, we have reached a period of the year when parents and guardians are compelled to make a final choice of the course which a medical student is to follow, for in a month's time all the medical schools in the metropolis and the provinces will be ready to open their doors for the winter session, and yet we shall probably have to wait some months more before the Committees and the formalists will be kind enough to carry out the instructions of the Senate. (British Medical fournal 1888;ii:502) 